experiences with sexual assault support services in co-operation with Umbrella Clinics.

Methods This study's objective was to explore teens' experiences following sexual assault by systematically reviewing and synthesizing published qualitative studies in this area. A narrative review of literature has been undertaken in order to identify publications that explore teens' experiences following sexual assault. Only studies focussed on teen participants (1319 years old), as opposed to retrospective accounts from adults, were included.

Results Important themes such as help-seeking behaviours, barriers, disclosure, the role of peers, importance of language, coping and gender emerged.

Conclusion This study identifies the complex nature of sexual assault specifically in combination with adolescence. Findings identify issues for service improvement and a significant need for research inclusive of adolescents' narratives.

Disclosure No significant relationships.

\section{P393 SITUATION ANALYSIS OF ADOLESCENT AND YOUNG FEMALES IN AKURE, ONDO STATE, NIGERIA}

Onesimus Aiwanfo*. Federal University of Technology Akure, Project Management, Akure, Nigeria

\subsection{6/sextrans-2019-sti.487}

Background Kids \& Teens Resource Centre, a non-government organisation working in the SRHR space in Nigeria conducted a situational analysis into the current status of Adolescents and Young Persons (AYPS) in Ondo State with a view to ascertaining the SRH challenges in various communities across Ondo state. This research also aimed at engaging AYPs in order to understand their knowledge, attitudes and practices as it pertains to sexual and reproductive health.

Methods A qualitative methodology was adopted for this study, using focus group discussions and key informant interviews. There were 18 FGDs and 101 KIIs conducted in all, during the primary research phase and desk research was conducted during the secondary research phase. In total, over 200 individual respondents were reached for this analysis.

Results 20\% of girls and women aged 10 to 24 in Ondo have undergone some degree of genital mutilation, Ondo state has the highest rate of teenage pregnancy in the South West with about 20 percent of young women from ages 13 to 19, four percent of young women aged 15 to 19 are married against their wish. And the policy environment has not been too friendly especially with implementation.

Conclusion Social mobilization advocacy for community stakeholders, including traditional and religious leaders.

Engaging AYPs to ensure that they are at the centre of any policies or intervention formulated for them.

Youth friendly centers should be built in every LGA and trained personals be put in those centres to attend to AYPSRHR.

Disclosure No significant relationships.

\section{P395 ACCEPTABILITY OF POINT OF CARE TESTING FOR CHLAMYDIA TRACHOMATIS IN ADOLESCENTS: IF WE MAKE IT, WILL THEY TAKE IT?}

Peter Pastolero, Amy Suss, Margaret Hammerschlag*. State University of New York Downstate Medical Center, Pediatrics, Brooklyn, USA

\subsection{6/sextrans-2019-sti.488}

Background Women 15-19 yo have the highest prevalence of C. trachomatis $(\mathrm{Ct})$ infection in the US. Despite the increase in the number of cases reported, chlamydia may still be under reported as the majority of patients do not have symptoms. Point of care tests (POCT) for Ct and other STIs are currently under development. Should these tests be made available for purchase over the counter (OTC)?

Methods An anonymous 12-item questionnaire was administered to patients attending the Adolescent clinic at University Hospital of Brooklyn, NY. The clinic serves an inner-city population that is predominantly African American and Caribbean American.

Results Completed questionnaires were obtained from 99 adolescents, 12-21 yo, median 18, 74 females, 25 males. 86 responders identified themselves as straight; 1 girl as gay, 12 as bisexual. Only $27 \%$ of responders ( $17 \%$ girls, $44 \%$ boys) reported an adequate knowlege of $\mathrm{Ct}$ infection including transmission and complications. 16 girls and 3 boys reported prior positive test for $\mathrm{Ct}$, all stated they were treated but 2 girls did not inform their sexual partners. Only $43.3 \%$ indicated that they would be interested in purchasing a Ct OTC (9(36\%) boys, 34(46\%) girls), 62\% were willing to pay $\$ 20$ or less. Although almost $100 \%$ indicated that they would report to their doctor and get treatment for partner, 4 would not inform their partners.

Conclusion Less than half of the respondants indicated they would buy an OTC for Ct if available. Many of these young people also had poor understanding of the transmission and risks of Ct infection. Cost was also an issue, with the majority willing to pay $\$ 20$ or less. Especially worrisome was that a small number were unwilling to notify their partners of a positive test, and had not done so in the past. The impact on linkage to care may have important public health implications. Disclosure No significant relationships.

\section{P397 INTRA-VAGINAL PRACTICES AMONG ADOLESCENT GIRLS AND YOUNG WOMEN IN SOUTH AFRICA: RISK FOR HIV ACQUISITION}

${ }^{1}$ Lorato Maje, ${ }^{2}$ Angela Kaida*, ${ }^{1}$ Scott Venners, ${ }^{3}$ Mags Bekinska, ${ }^{4}$ Stefanie Hornschuh, ${ }^{2}$ Patricia Smith, ${ }^{1}$ Mark Brockman, ${ }^{5}$ Thumbi Ndung'U, ${ }^{6}$ Glenda Gray, ${ }^{7}$ Jenni Smit, ${ }^{8}$ Janan Dietrich. 'Simon Fraser University, Faculty of Health Sciences, Burnaby, Canada; ${ }^{2}$ Faculty of Health Sciences, Simon Fraser University, Burnaby, Canada; ${ }^{3}$ University of the Witwatersrand, Maternal Adolescent and Child Health Research Unit, Durban, South Africa; ${ }^{4}$ University of the Witwatersrand, Faculty of Health Sciences-Perinatal HIV Research Unit (PHRU), Johannesburg, South Africa; ${ }^{5}$ University of the KwaZulu Natal, HIV Pathogenesis Programme and Africa Health Research Institute, Durban, South Africa; ${ }^{6}$ South African Medical Research Council, Cape Town, South Africa; 'University of the Witwatersrand, Match Research Unit (MRU), Department of Gynaecology and Obstetrics, Faculty of Health Sciences, Johannesburg, South Africa; ${ }^{8}$ Perinatal HIV Research Unit (PHRU), Faculty of Health Sciences, University of the Witwatersrand, Johannesburg, South Africa

\subsection{6/sextrans-2019-sti.489}

Background Women around the world use intra-vaginal practices (IVPs) for varying reasons. IVPs can disrupt the vaginal microbiome and induce inflammation, increasing susceptibility 